THE JOURNAL OF OHBMIOAL INDUSTEY, TORYO, JAPAN.

VOL. XVIII. JUNE, I9I5. No. 208.

ABSTRACTS FROM THE ORIGINAL ARTICLES.

\title{
ON THE HARDENING OF OILS.
}

! by Seiichi Ueno.

The author has studied the hydrogenation of fatty oils. The chief subjects are as follows :

I. Some experiments on various oils.

2. Hydrogenation of sardine oil on a semi-industrial scale.

3. Examination of the intermediate products of hydrogenation.

4. Durability of the activity of nickel and revivification of spent catalyser.

5. Hydrogenation of oils and unsaturated acids at low temperatures.

6. Relation of the catalytic activity of nickel-kieselguhr-catalyser to the proportions of nickel and its carrier (kieselguhr).

ON THE COMPARISON OF THE RICES OF FORMOSA AND JAPAN Proper--Preliminary Paper.

by Tetsukichi Katayama, Kogakushi.

The author is devoted to investigating the properties of the rices of Formosa and Japan proper. The important results obtained are as follows :

I. That each rice shows the same analytical results and the only difference is in the properties of the starch contained.

2. The boiled Formosan rice is saccharified more slowly by means of yeast than the boiled Japanese proper; but if boiled to paste or after 
powdering, the difference in this process becomes much less.

3. The reducing power of the saccharified liquor of boiled Formosan rice is higher than that of Japanese proper. 